\title{
Dispersion of Alpha-Nuclides during Animal Experiments
}

\author{
Kazuko KANEDA-NAKASHIMA ${ }^{1), 2)^{*}}$, Zijian ZHANG $^{2), 3)}$, Kojiro NAGATA ${ }^{2), 4)}$, Kenji SHIRASAKI ${ }^{5)}$, \\ Hidetoshi KIKUNAGA ${ }^{6)}$, Tomoo YAMAMURA ${ }^{5), 7)}$, Kazuhiro $\mathrm{OOE}^{8)}$, Tadashi WATABE ${ }^{8)}$, \\ Atsushi TOYOSHIMA ${ }^{1), 2)}$, Takashi YOSHIMURA ${ }^{2), 4), 9)}$, and Atsushi SHINOHARA ${ }^{1), 2), 3)}$ \\ ${ }^{1)}$ Division of Science, Institute for Radiation Sciences, Osaka University, Toyonaka, Osaka 560-0043, Japan \\ ${ }^{2)}$ Project Research Center for Fundamental Sciences, Graduate School of Science, Osaka University, Toyonaka, Osaka 560-0043, Japan \\ 3) Department of Chemistry, Graduate School of Science, Osaka University, Toyonaka, Osaka 560-0043, Japan \\ 4) Radioisotope Research Center, Institute for Radiation Sciences, Osaka University, Suita, Osaka 565-0871, Japan \\ 5) Laboratory of Alpha-Ray Emitters, Institute for Materials Research, Tohoku University, Sendai, Miyagi 980-8577, Japan \\ 6) Research Center for Electron Photon Science, Tohoku University, Sendai, Miyagi 982-0826, Japan \\ 7) Institute for Integrated Radiation and Nuclear Science, Kyoto University, Kumatori, Osaka 590-0494, Japan \\ ${ }^{8)}$ Department of Nuclear Medicine and Tracer Kinetics, Graduate School of Medicine, Osaka University, Suita, Osaka 565-0871, Japan \\ 9) Division of Safety Management, Institute for Radiation Sciences, Osaka University, Toyonaka, Osaka 560-0043, Japan
}

Received May 19, 2021; accepted Sep. 21, 2021

The dispersions of short-lived radionuclides emitting $\alpha$-particles, such as ${ }^{223} \mathrm{Ra},{ }^{211} \mathrm{At}$, and ${ }^{225} \mathrm{Ac}$, during animal experiments were measured for radiation safety management. These three radionuclides dispersed from mice were trapped using charcoal-impregnated filters, and those in feces were collected directly, and those in urine were recovered with bedding in a breeding cage. For all the radionuclides, uptakes by tissues were also further examined after dissection. The radioactivity of each radionuclide was evaluated with a $\gamma$-ray scintillation counter using daughter nuclide. In tumor bearing mice, ${ }^{211} \mathrm{At}$ and ${ }^{223} \mathrm{Ra}$ accumulated in tumor tissues with high affinity and less accumulated in other tissues. It was noted that all the three radionuclides were not exhausted or evaporated from the breeding cages and the peak of excretions of the radionuclides in the animal experiments was observed within twenty-four hours.

Key Words: animal experiment, Radium-223, Astatine-211, Actinium-225, dispersions

[doi:10.12950/rsm.210519]

1. Introduction

In Japan, $50 \%$ of individuals will experience cancer in their lifetimes ${ }^{1)}$. The development of a more effective anti-tumor drug is, therefore, an urgent task. In recent years, the application of short-lived radionuclides emitting $\alpha$-particles to nuclear medicine has garnered increasing attention. At present, the $\beta$-particle emitters such as ${ }^{131} \mathrm{I}$ and ${ }^{90} \mathrm{Y}$ have been already used as nuclear medicine for the treatment of thyroid cancer and CD20 positive lymphoma, respectively. Because of the nature of an $\alpha$-particle as short range and high linear-energy-

Division of Science, Institute for Radiation Sciences, Osaka University,

Toyonaka, Osaka 560-0043, Japan transfer, cytotoxic and anti-tumor effects are highly promising and damage on normal cells surrounding tumor cells is expected to be reduced. For the clinical use of short-lived $\alpha$-emitters such as ${ }^{211} \mathrm{At}$ and ${ }^{225} \mathrm{Ac}$ in the near future, data on their dispersion are of great importance for the radiation protection and safety management. To our knowledge, the dispersion of short-lived $\alpha$-emitters in an animal experiment has been rarely reported.

${ }^{223} \mathrm{Ra}$ with a half-life $\left(T_{1 / 2}\right)$ of 11.4 days is the first $\alpha$-emitter approved for the nuclear medicine treatment in the form of an

E-mail: kkaneda@irs.osaka-u.ac.jp

Tel: +81-6-6850-5813; Fax +81-6-6850-8230 


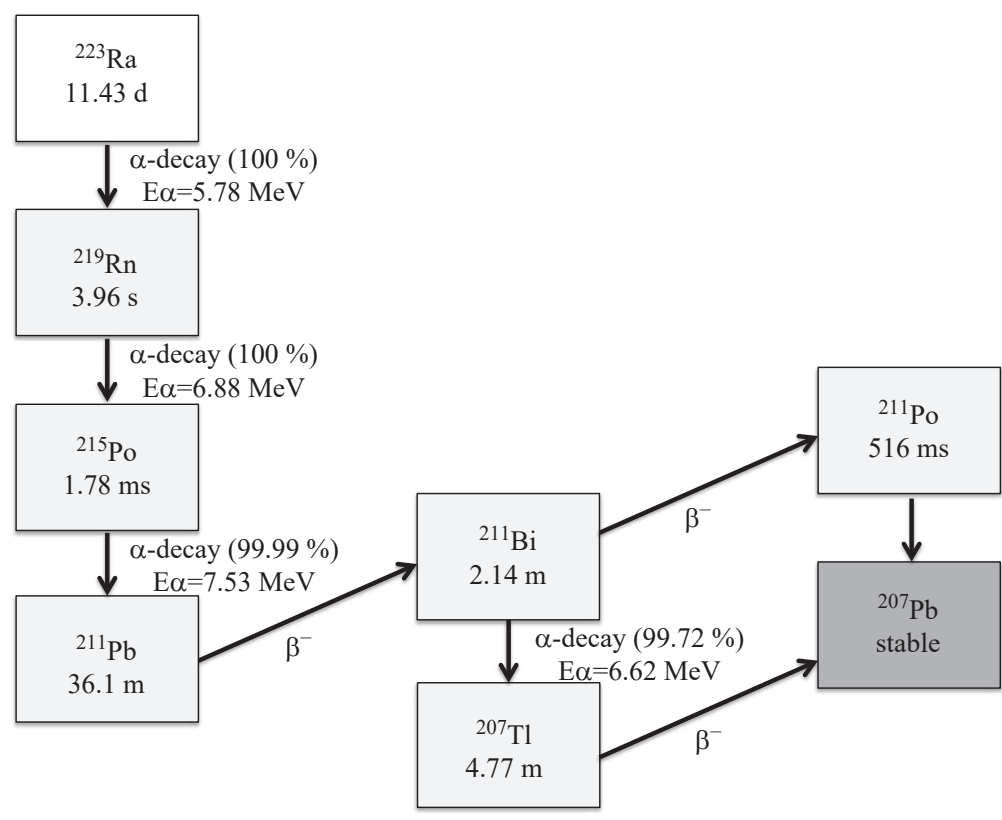

Fig. 1a. Decay scheme for ${ }^{223} \mathrm{Ra}$. This scheme was draw by modified the data from data book ${ }^{20)}$.

aqueous solution of radium chloride $\left(\mathrm{Xofigo}^{\circledR}{ }^{\circledR 2-4)}\right.$. In the decay series of ${ }^{223} \mathrm{Ra}$, this finally disintegrates into stable ${ }^{207} \mathrm{~Pb}$ by $\alpha$ and $\beta$-particle emissions as illustrated in Fig. 1a. ${ }^{211} \mathrm{At}$ $\left(T_{1 / 2}=7.2\right.$ hours) which is producible with an accelerator is one of the most practicable candidates for the targeted $\alpha$ therapy in Japan. The radionuclide decays via the $\alpha$-emission $(42 \%)$ and the electron capture (58\%) as depicted in Fig. $1 \mathrm{~b}$. The descendent nuclide ${ }^{211} \mathrm{Po}\left(T_{1 / 2}=0.5 \mathrm{sec}\right)$ formed from ${ }^{211}$ At by electron capture immediately disintegrates by $100 \%$ $\alpha$-decay. For ${ }^{225} \mathrm{Ac}\left(T_{1 / 2}=10.0\right.$ days), many clinical studies have been so far carried out and the remarkable anti-tumor effects have been reported in the treatment of castration-

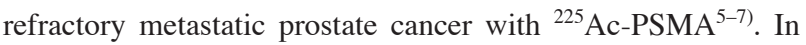
the decay series of ${ }^{225} \mathrm{Ac}$, this disintegrates into ${ }^{209} \mathrm{Bi}$ by $\alpha$ - and $\beta$-particle emissions as shown in Fig. 1c.

The dispersal rate of ${ }^{219} \mathrm{Rn}$ from aqueous ${ }^{223} \mathrm{Ra}$ solution has been already reported ${ }^{8}$. In human, it is reported that the amount of ${ }^{223} \mathrm{Ra}$ in the exhaled breath is relatively small after injection ${ }^{9}$. Although the dispersal rate of ${ }^{225} \mathrm{Ac}$ has been also reported $^{10)}$, there is no report about animal experiments. In this study, we investigated the dispersions of ${ }^{223} \mathrm{Ra},{ }^{211} \mathrm{At}$, and ${ }^{225} \mathrm{Ac}$ out of mice in a mouse cage during the breeding after the administration of these nuclides. Normal and tumor-bearing mice were provided to examine the influence of the accumulation of ${ }^{223} \mathrm{Ra}$ and ${ }^{211} \mathrm{At}$ in a tumor. ${ }^{225} \mathrm{Ac}$ is always

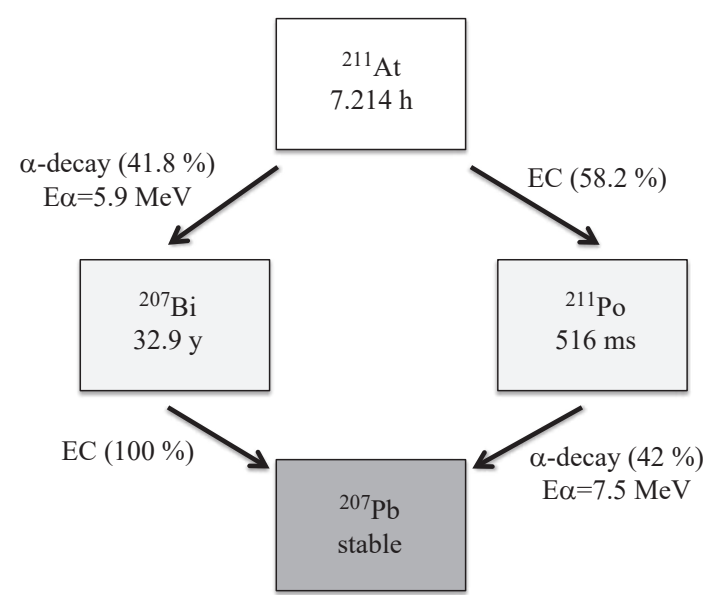

Fig. 1b. Decay scheme for ${ }^{211}$ At.

used as ${ }^{225} \mathrm{Ac}$-labeling compounds or antibodies. It is because no cancer types that ${ }^{225} \mathrm{Ac}$ particularly accumulates in have been reported unlike ${ }^{223} \mathrm{Ra}$ or ${ }^{211} \mathrm{At}$. Because of this, tumorbearing mice were not used for ${ }^{225} \mathrm{Ac}$. In addition, the washingout yields of the radionuclides from the breeding cage used were investigated because cage cleaning is indispensable for raising animals.

Compounds labeled with $\alpha$-ray emitting nuclides may be metabolized in the body and the $\alpha$-ray emitting nuclides may be released from those compounds. In order to investigate the 


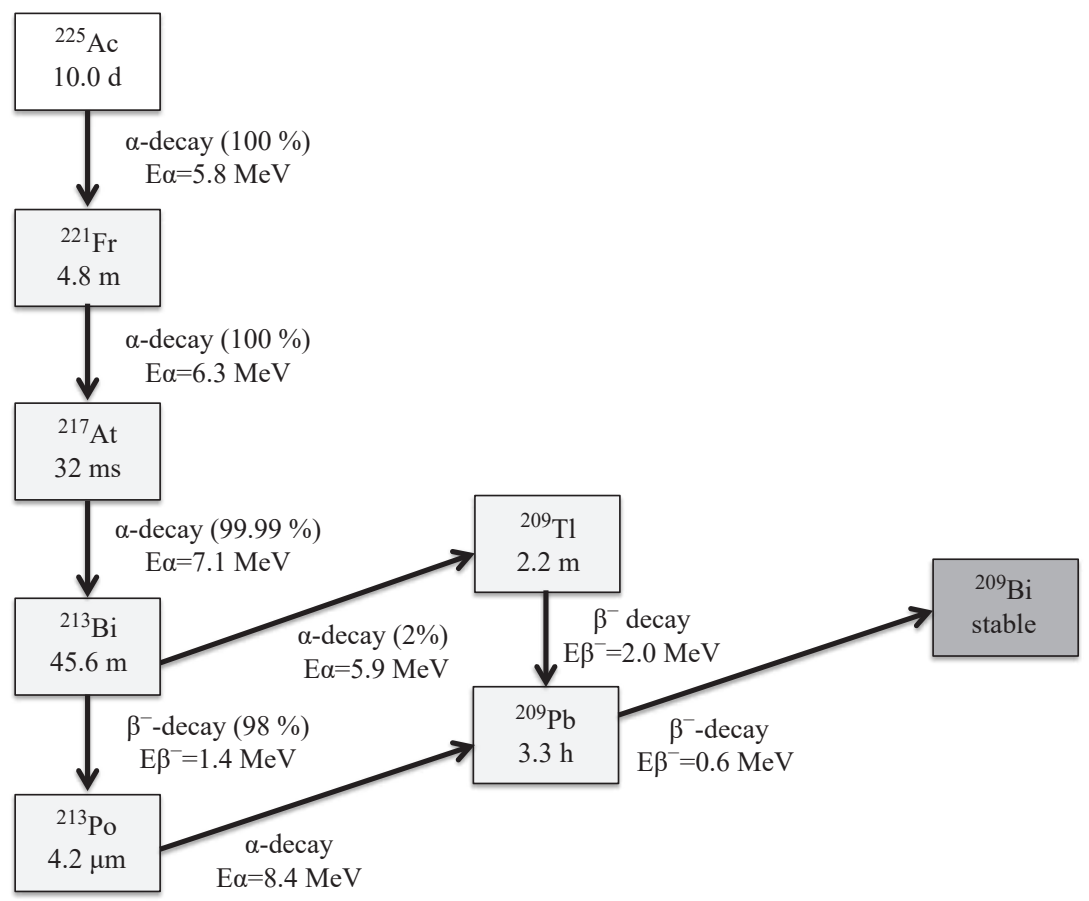

Fig. 1c. Decay scheme for ${ }^{225}$ Ac.

excretion of labeled compounds from the body, it is important to first investigate the properties of the alpha-ray emitting nuclides themselves in excretion.

\section{Materials and Methods}

\section{2-1. Materials}

Aqueous solutions containing ${ }^{223} \mathrm{Ra}$ was provided by Bayer HealthCare Pharmaceuticals $\mathrm{Inc}^{8}$. We diluted the $\mathrm{RaCl}_{2}$ solution with saline for injection to mice. The radioactivity of ${ }^{223} \mathrm{Ra}$ was determined using a germanium $(\mathrm{Ge})$ detector (BE2020, Canberra) calibrated with ${ }^{133} \mathrm{Ba}$ and ${ }^{152} \mathrm{Eu}$ standard radiation sources.

${ }^{211}$ At was produced in the ${ }^{209} \operatorname{Bi}(\alpha, 2 n){ }^{211}$ At reaction using the K140 AVF cyclotron at Research Center of Nuclear Physics, Osaka University. ${ }^{211}$ At was separated from the ${ }^{209} \mathrm{Bi}$ target by dry distillation according to the literature procedures ${ }^{11,12)}$. The aqueous solution containing ${ }^{211}$ At was obtained by dissolution of ${ }^{211} \mathrm{At}$ in distilled water. The radioactivity of ${ }^{211} \mathrm{At}$ was determined as same as ${ }^{223} \mathrm{Ra}$.

${ }^{225} \mathrm{Ac}$ was obtained by the literature method which is milking from its grandmother nuclide ${ }^{229} \mathrm{Th}^{10,13,14)}$. After ${ }^{225} \mathrm{Ac}$ solution was evaporated to dryness, the residue was dissolved in saline. The radioactivity of ${ }^{225} \mathrm{Ac}$ was determined using the Ge detector.
We also measured control sample of all nuclides by a Curie meter (IGC-7, HITACHI) and a $\gamma$-counter (2480 Wizard $^{2}$, PerkinElmer) for calculating the amount of each radionuclide.

\section{2-2. Animals}

Animals were purchased from SLC Japan (Shizuoka, Japan). We prepared ddY mice (5 weeks old, male) and ICR mice ( 5 weeks old, male or female) as normal mice. Mice were housed three or five to a cage and maintained in rooms under a regular twelve hours light-dark cycle. After one week of habituation, these animals were used for the experiments. We also prepared tumor-bearing mouse models, particularly Balb/ c-nu/nu mice ( 5 weeks old, male). Tumor transplantation was performed after one week of habituation. The protocol was approved by the Animal Care and Use Committee of the Osaka University Graduate School of Science.

\section{2-3. Cells}

Cancer cells were obtained from the RIKEN cell bank. A prostate cancer cell line, PC-3, was maintained in RPMI 1640 culture medium. Medium were purchased from Sigma Aldrich Japan and supplemented with $10 \%$ heat-inactivated fetal bovine serum (GIBCO) and a 1\% antibiotic solution (Fujifilm Wako). K1-NIS, human thyroid cancer K1 cells with overexpression of 
the sodium/iodide symporter (NIS, SLC5A5) ${ }^{15)}$ were maintained in culture medium which was already reported.

\section{2-4. Preparation of tumor-bearing mice}

Transplantations were performed after the habituation of the animals used for experiments. A cranial metastasis model for ${ }^{223} \mathrm{Ra}$ was established by subcutaneously transplanting $1 \times 10^{6}$ PC-3 cells to the parietal region ${ }^{16)}$. A subcutaneous tumor model for ${ }^{211}$ At was established by transplanting $1 \times 10^{7}$ K1-NIS cells. K1-NIS cells were mixed respectively with Matrigel (Corning) as a basement membrane matrix, and then transplanted. The engrafted animals were used for the subsequent experiments. Mice were maintained for two weeks and used for the subsequent experiments.

\section{2-5. Dispersion measurements from mice}

To evaluate the dispersions of ${ }^{223} \mathrm{Ra},{ }^{211} \mathrm{At}$, and ${ }^{225} \mathrm{Ac}$ during the experiments using mice, all the excretions were collected, and the air which may contain the exhalation and aerosols such as a urine vapor in a cage.

\section{2-5-1. Equipment for collecting nuclide from mice}

A disposable inner-cage (Natsume Seisakusho Co., Ltd., $\mathrm{KN}-800-601)$ was set in an outer cage (Natsume Seisakusho, $\mathrm{KN}-600-\mathrm{T}$ ) to prevent cross-contamination on the inner surface of the outer cage. A charcoal-impregnated filter (ESKO, EA929F-2, charcoal: $150.0 \mathrm{~g} / \mathrm{m}^{2}$, thickness: $1.8 \mathrm{~mm}$ ) was cut and fixed on a grid-like upper lids of the cage with adhesive tape to collect the dispersed radionuclides. Breeding tools for sample collection were set up like in Fig. 2(a). During experiments, any alpha count was not detected using an $\alpha$-survey meter on outside of the charcoal-impregnated filter, while alpha counts were detected on inner mice side. This indicates that the radionuclide cannot pass through the charcoal-impregnated filter and are kept inside of the cage. Weighed bedding (Enviro-dri ${ }^{\circledR}$, Shepherd Specialty Papers) of $100.0 \mathrm{~g}$ to soak urine was spread over the bottom of the cage. Drinking water for a mouse was supplied via the transport agar (Oriental Yeast Co., Ltd.) to keep the lid closed during collection of the dispersed radionuclides. For each mouse, approximately $5.0 \mathrm{~g}$ of the irradiated CRF-1 (Oriental Yeast Co., Ltd.) was supplied in a day. A $0.1 \mathrm{~mL}$ of the ${ }^{223} \mathrm{Ra},{ }^{221} \mathrm{At}$, or ${ }^{225} \mathrm{Ac}$ aqueous solution was intravenously administered from a tail vein with a $27-\mathrm{G}$ syringe (FN, TERUMO). The administrated radioactivity of ${ }^{223} \mathrm{Ra}$ was $9.90 \pm 0.10 \mathrm{kBq} /$ mouse and ${ }^{225} \mathrm{Ac}$ was $9.87 \pm 0.04 \mathrm{kBq} /$ mouse, and ${ }^{211} \mathrm{At}$ was $1.06 \pm 0.04 \mathrm{MBq} /$ mouse.

\section{2-5-2. Collecting nuclide from mice and their procedures of measure}

After the administration, the bedding was mixed to uniform distribution of the radionuclides excreted as urine, and then a part of the bedding was taken and weighed. The amount of radionuclide in urine was measured using the bedding sample taken out from the cage, and the total amount of radionuclide was quantified. In addition, the amount of urine was evaluated from the amount of increase in the bedding. To evaluate the remaining amounts of nuclides in the bodies, the mice were dissected. The soft tissues of cerebrum, thyroid, salivary gland, heart, lung, thymus (normal animals only), liver, stomach, small intestine, large intestine, cecum, kidney, adrenal gland, pancreas, spleen, bladder, testis (males only), and ovary (females only), and the hard tissues of sternum, cervical spinal cord, thoracic spinal cord, ribs, femur, skull, and coccyx were measured. In addition to the urine absorbed in the bedding, urine was also collected from the bladder at the time of dissection. Subcutaneous tumor, and organs which were found metastasis tissues were classified as tumor tissues. Blood was collected via cardiac puncture. All residue adhering to the dissection tools or wiping material, whether blood or pieces of muscle, was also collected. These organ samples separately sealed in plastic bags were then subjected to the $\gamma$-counter. The samples of ${ }^{223} \mathrm{Ra}$ and ${ }^{225} \mathrm{Ac}$ were stored more than 12 hours after the collection of the samples to establish the radioactive equilibria.

\section{2-5-3. Washing out of the cages}

After removing the mice, feces, and bedding from the inner cages, the cages used were wiped with paper towels three times (Kim-towel, Kimberly Clark Corp). After wiping up, $20 \mathrm{~mL}$ of distilled water was added to each cage. After put into $20 \mathrm{~mL}$ of purified water into the cage and shook 10 times, the water used was collected. This procedure was repeated 5 times (Fig. 2(b)). The paper towels wiped and wash water were also separately measured by $\gamma$-counter.

\section{2-6. Measure of radionuclides}

For ${ }^{223} \mathrm{Ra}$, the region of interest was set to be $220-440 \mathrm{keV}$ to detect $\gamma$-rays of ${ }^{223} \mathrm{Ra}(269 \mathrm{keV})$ and its descendants $\left({ }^{219} \mathrm{Rn}\right.$ : $271 \mathrm{keV}, 402 \mathrm{keV},{ }^{211} \mathrm{~Pb}$ : 405, $\left.427 \mathrm{keV},{ }^{211} \mathrm{Bi}: 351 \mathrm{keV}\right)$. Each 
(a)

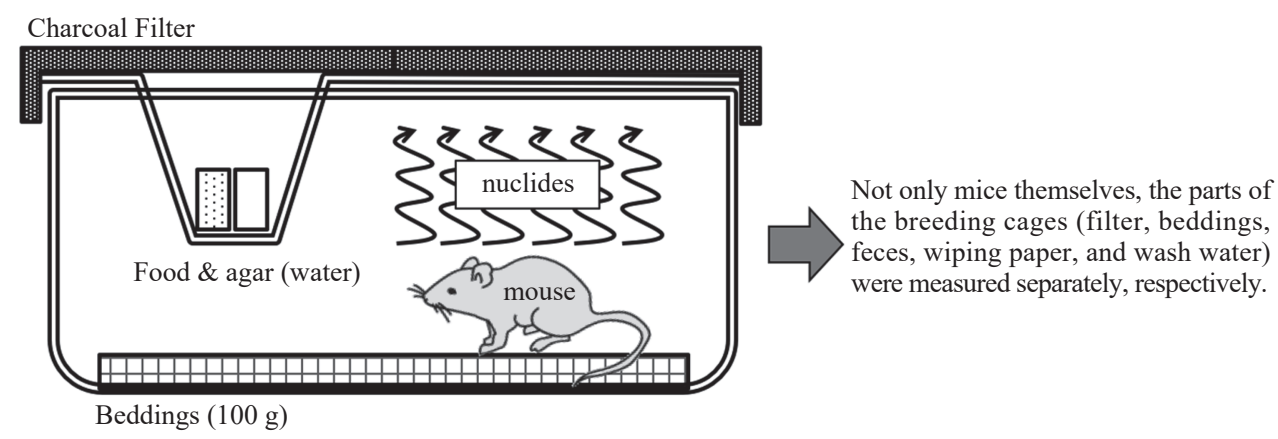

(b)

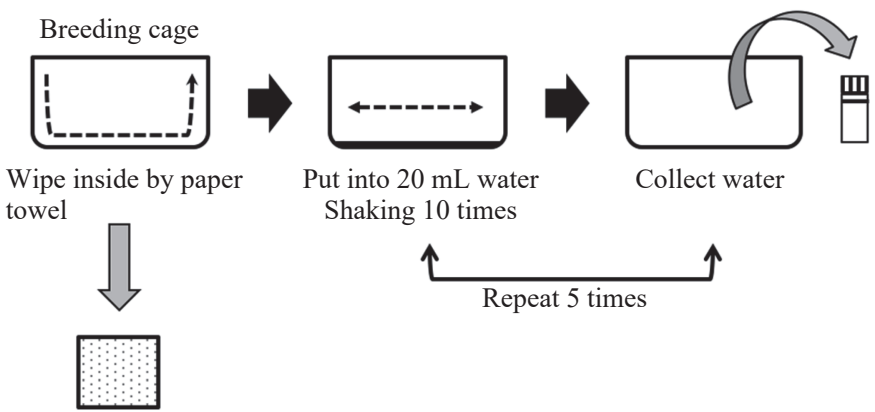

Fig. 2. Equipment for collecting nuclide from mice and their procedures. (a) Schematic figure of breeding cage. (b) Procedure of washing the cage.

sample of ${ }^{223} \mathrm{Ra}$ was measured for two minutes. For ${ }^{211} \mathrm{At}$, the region of interest was set at $15-150 \mathrm{keV}$ which simply covers $79 \mathrm{keV}$ characteristic X-ray peak of ${ }^{211} \mathrm{Po}$ attributed to the electron-capture decay of ${ }^{211}$ At. Each Sample of ${ }^{211}$ At was measured for 1 minute. For ${ }^{225} \mathrm{Ac}$, the descendant nuclide ${ }^{213} \mathrm{Bi}$ (440 keV) was counted with the $\gamma$-counter when equilibrium was reached and decay-corrected as a representative measurement of ${ }^{225} \mathrm{Ac}$ in the sample. Each sample was counted for three minutes, with energy windows of 170-270 keV for ${ }^{221} \mathrm{Fr}(218 \mathrm{keV})$ and $380-520 \mathrm{keV}$ for ${ }^{213} \mathrm{Bi}$. $\gamma$-rays of the samples of the charcoal-impregnated filters, beddings, feces, and organs were measured in an automatic $\gamma$-counter automatically. The obtained counts were used with those of control samples for calculation of amounts.

\section{2-7. Calculation of dispersion amounts}

For evaluation of dispersion, we calculated the amounts of nuclides using formula (i).

$$
A_{\text {sample }}=A_{\text {measure }}\left(\frac{1}{2}\right)^{-\frac{t}{T}}
$$

$A_{\text {sample }}$ represents the radioactivity of samples with a correction for radioactive decay and $A_{i n j}$ is the dose injected. $A_{\text {measure }}$ represents the radioactivity calculated using the count of each samples measured by the $\gamma$-counter. T represents half-time of each nuclide $\left(\mathrm{T}_{1 / 2}\right)$ and $\mathrm{t}$ represent the elapsed time since measuring the control. $A_{i n j}$ was calculated using formula (ii).

$$
A_{\text {inj }}=S_{\text {pre }}-S_{\text {post }}
$$

$S_{\text {pre }}$ represents value of syringe pre-injection and $S_{\text {post }}$ represents value of syringe post-injection with a correction for radioactive decay. It is needed to consider the percentage of injected dose (\% ID) for evaluation of distribution from animal experiments. The $\%$ ID can be calculated by the following formula:

$$
\% \mathrm{ID}=\frac{A_{\text {sample }}}{A_{\text {inj }}} \times 100
$$

\section{Results and Discussion}

\section{3-1. Distribution of nuclides}

The mean distribution of excreted and internal ${ }^{223} \mathrm{Ra}$ for the normal mice and the cranial metastasis model mice are summarized in Table 1. The values for both the normal and tumor model mice were calculated from five mice. It was confirmed that ${ }^{223} \mathrm{Ra}$ had been accumulated in normal bone and tumor tissue. The radioactivity percentages detected in the 
Table 1 Evaluated \%ID (percentage of observed radioactivity) of ${ }^{223} \mathrm{Ra}$ in normal and tumor-bearing mice at 24 and $48 \mathrm{hrs}$ after the administration. ddY mice was used for normal $(\mathrm{N}=5)$, and Balb/c-nu/nu with PC-3 cells was used for tumor bearing $(\mathrm{N}=5)$. Injection dose was $9.90 \pm$ $0.10 \mathrm{kBq} / \mathrm{mouse}$. hrs: hours, -; no data, Data was shown in Mean \pm S.E.

\begin{tabular}{cccc}
\hline & \multicolumn{1}{c}{$\begin{array}{c}\text { Collect } \\
\text { time }\end{array}$} & Normal & Tumor bearing \\
\hline Soft & $24 \mathrm{hrs}$ & $16.13 \pm 1.55$ & $17.45 \pm 0.87$ \\
\cline { 2 - 4 } tissues & $48 \mathrm{hrs}$ & $12.63 \pm 1.24$ & $16.62 \pm 1.15$ \\
\hline \multirow{2}{*}{ Bones } & $24 \mathrm{hrs}$ & $39.49 \pm 3.79$ & $18.34 \pm 1.38$ \\
\cline { 2 - 4 } & $48 \mathrm{hrs}$ & $37.42 \pm 1.39$ & $16.42 \pm 0.41$ \\
\hline \multirow{2}{*}{ Tumor } & $24 \mathrm{hrs}$ & - & $16.13 \pm 1.55$ \\
\cline { 2 - 4 } & $48 \mathrm{hrs}$ & - & $11.08 \pm 0.62$ \\
\hline \multirow{2}{*}{ Feces } & $24 \mathrm{hrs}$ & $16.25 \pm 3.05$ & $17.75 \pm 5.61$ \\
\cline { 2 - 4 } & $48 \mathrm{hrs}$ & $19.08 \pm 0.70$ & $14.78 \pm 4.92$ \\
\hline \multirow{2}{*}{ Bedding } & $24 \mathrm{hrs}$ & $28.14 \pm 0.53$ & $33.28 \pm 3.18$ \\
\cline { 2 - 4 } & $48 \mathrm{hrs}$ & $30.88 \pm 0.63$ & $42.64 \pm 4.43$ \\
\hline Charcoal & $24 \mathrm{hrs}$ & $0.0030 \pm 0.00010$ & $0.16 \pm 0.017$ \\
\cline { 2 - 4 } Filter & $48 \mathrm{hrs}$ & $0.0050 \pm 0.0010$ & $0.022 \pm 0.0023$ \\
\hline
\end{tabular}

charcoal-impregnated filter during twenty-four hours were $0.0036 \%$ ID in the normal mice and $0.16 \%$ ID in the tumor model mice. This suggests that administered ${ }^{223} \mathrm{Ra}$ and its descendent radionuclides in the vein injection were less exhaled by the breath and was hard to disperse as aerosols from beddings in both the normal and tumor model mice. Although its daughter ${ }^{219} \mathrm{Rn}$ is a radionuclide of a volatile noble-gas, its $T_{1 / 2}$ of $3.96 \mathrm{sec}$ is too short to be dispersed. For all the mice, approximately $50 \%$ ID of injected ${ }^{223} \mathrm{Ra}$ were excreted as the urine and feces. It was thought that the excreted fractions as a sum of the urine and the feces at twenty-four hours after the administration were probably simply due to metabolism. The excreted percentages of ${ }^{223} \mathrm{Ra}$ for the tumor-bearing mice were similar to those for the normal mice. However, ${ }^{223} \mathrm{Ra}$ clearly accumulated in tumor and tumor metastasis tissues and was decreased in normal tissues comparing with the result on the normal mice. The excretion of ${ }^{223} \mathrm{Ra}$ as feces has already been reported from Bayer AG's chemical data ${ }^{2}$. We confirmed the excreted rate of ${ }^{223} \mathrm{Ra}$ from experimental mice was almost the same as that reported from Bayer AG's.
Table 2 Evaluated \%ID (percentage of observed radioactivity) of ${ }^{211} \mathrm{At}$ in normal and tumor-bearing mice at 24 hrs after the administration. ddY mice was used for normal $(\mathrm{N}=5)$, and Balb/c-nu/nu with K1-NIS cells was used for tumor bearing $(N=5)$. Injection dose was $1.06 \pm 0.04$ $\mathrm{MBq} / \mathrm{mouse}$. rs: hours, -; no data, Data was shown in Mean \pm S.E.

\begin{tabular}{ccc}
\hline & Normal & Tumor bearing \\
\hline Soft tissues & $15.85 \pm 0.0092$ & $25.75 \pm 2.08$ \\
\hline Tumor & - & $14.66 \pm 1.13$ \\
\hline Bones & $0.44 \pm 0.00059$ & $0.85 \pm 0.039$ \\
\hline Feces & $1.63 \pm 0.49$ & $1.30 \pm 0.0027$ \\
\hline Bedding & $81.95 \pm 16.90$ & $56.08 \pm 9.12$ \\
\hline Charcoal filter & $0.14 \pm 0.00$ & $1.37 \pm 0.10$ \\
\hline
\end{tabular}

Table 2 lists the amounts of the excreted and internal ${ }^{211} \mathrm{At}$ for the normal and tumor-bearing mice during twenty-four hours after the injection. For both the types of the mice, the percentages of ${ }^{211}$ At detected in the filter were very low even at twenty-four hours after the administration despite of high volatility of At. Most of ${ }^{211}$ At was excreted as the urine in the bedding and its small parts were in the feces. The externally discharged percentage of ${ }^{211}$ At as a sum of the feces, urine, and exhalation for the normal mice was higher than that for the tumor-bearing mice. In the tumor bearing mice, it seems that ${ }^{211}$ At was accumulated in tumor tissues with giving anti-tumor effects ${ }^{15)}$. Clearance of ${ }^{211} \mathrm{At}$ in the normal mice was faster than that of the tumor bearing mice. Once nuclides accumulated in the tumor tissues, there is a time lag in the excretion of nuclides as compared with normal animals without tumor. The difference was clearly seen when imaging was actually performed in the cancer-bearing model ${ }^{15)}$. From these results, ${ }^{211}$ At is expected to accumulate more in a targeted tumor, leading to less accumulation in normal tissues in a realistic use of ${ }^{211}$ At-labelled pharmaceuticals.

In Table 3, excreted ${ }^{225} \mathrm{Ac}$ for the normal mice at twentyfour and forty-eight hours after the injection were listed. The amount of excreted ${ }^{225} \mathrm{Ac}$ in urine or feces were very small. Most of ${ }^{225} \mathrm{Ac}$ was accumulated in the soft tissues and bones. However, because distributions and excretions of the ${ }^{225} \mathrm{Ac}$ labeled compound actually depend on their biochemical properties ${ }^{13,14)}$, dispersion of ${ }^{225}$ Ac labeled compounds would be extremely low unless a labelled compound is volatile.

In addition, we tracked distributions of ${ }^{211} \mathrm{At}$ and ${ }^{225} \mathrm{Ac}$ after 
forty-eight hours from injection. The ddY is the strain that has been widely used in Japanese pharmacokinetic studies. Since ddY mice were also used for experiments in distribution of radioisotopes so far, we used this strain for comparison of tumor bearing models. However, ICR mice are increasing in use worldwide, thus ICR mice were used for comparison between males and females. The reason for measuring the sex difference was to confirm whether there was a difference in the routes and amounts of nuclide excretion. In Table 4, data of

${ }^{211}$ At for 4 days are listed. After 4 days, the measurements were not carried out because radioactivity of all the samples decays down to a background level. Interestingly, there was a difference between the sexes in excreted urine. However, comparing excretion amounts of urine between sexes, males

Table 3 Evaluated \%ID (percentage of observed radioactivity) of ${ }^{225} \mathrm{Ac}$ in normal mice at 24 and $48 \mathrm{hrs}$ after the administration. ddY mice was used for normal $(N=5)$. Injection dose was $9.87 \pm 0.04 \mathrm{kBg} /$ mouse. hrs: hours. Data was shown in Mean \pm S.E.

\begin{tabular}{ccc}
\hline & Collect time & Normal \\
\hline \multirow{2}{*}{ Soft tissues } & $24 \mathrm{hrs}$ & $64.01 \pm 0.87$ \\
\cline { 2 - 3 } Bones & $48 \mathrm{hrs}$ & $64.01 \pm 2.64$ \\
\cline { 2 - 3 } & $24 \mathrm{hrs}$ & $25.09 \pm 0.90$ \\
\hline \multirow{2}{*}{ Feces } & $48 \mathrm{hrs}$ & $24.59 \pm 0.88$ \\
\cline { 2 - 3 } & $24 \mathrm{hrs}$ & $1.08 \pm 0.72$ \\
\hline \multirow{2}{*}{ Bedding } & $48 \mathrm{hrs}$ & $0.56 \pm 0.087$ \\
\cline { 2 - 3 } & $24 \mathrm{hrs}$ & $9.80 \pm 1.22$ \\
\hline \multirow{2}{*}{ Charcoal Filter } & $48 \mathrm{hrs}$ & $10.83 \pm 0.78$ \\
\cline { 2 - 3 } & $24 \mathrm{hrs}$ & $0.020 \pm 0.014$ \\
\hline
\end{tabular}

had larger than those of females. In other words, the difference in urine excretion was considered to be simply due to the large amount of urine. In Table 5, data of ${ }^{225} \mathrm{Ac}$ for 12 days are listed. At the elapse of 12 days, the measurements were stopped because radioactivity of all the samples were at background level. We also found that the time when large amount of ${ }^{225} \mathrm{Ac}$ was dispersed until twenty-four hours. After more than twentyfour hours, there was no large amount of excretions of nuclides. Amount of excretions were decrease in time.

\section{3-2. Washing out yields of cages}

Washing the equipment is essential in animal experiments. Breeding cages should be washed to keep them clean. However, there are no reports of how dirty the cages of nuclide-treated animals are and how they can be removed. In this study, we measured the amount of emissions when washing cages in order to understand the status of decontamination during cage cleaning. In Tables 6-8, variations of the washing-out yields of ${ }^{223} \mathrm{Ra},{ }^{211} \mathrm{At}$, and ${ }^{225} \mathrm{Ac}$, respectively, were shown. In all the radionuclides, the washing-out yields were very low and almost all the radioactivity was stripped by the paper towel, and the remaining is washed out by the first washing. The administered ${ }^{211}$ At was mainly excreted in the urine and feces. It is better to wipe a cage with a paper towel before washing the cage to remove the remaining radionuclides in animal experiments.

\section{3-3. Dispersion pattern of alpha emitting nuclides}

Dispersions of three nuclides from animal experiment, their peak might be within twenty-four hours (Table 1, 4, 5). Especially in ${ }^{211}$ At itself, the peak of emission was three hours (Data not shown). The kinetics of the radio-labeled compounds in the animals, depend on the nature of the compound itself. In fact, the distribution or dispersion rate of the ${ }^{225} \mathrm{Ac}$ labeled chemicals ${ }^{17)}$ or the ${ }^{211}$ At labeled chemicals ${ }^{18)}$ are different from

Table 4 Evaluated \%ID (percentage of observed radioactivity) of excreted ${ }^{211}$ At from normal mice after the administration. Day 1 (24 hrs), and Day 2 to 4, ICR mice was used for this experiment. Each group was consisted with three mice $(\mathrm{N}=3)$. Injection dose was $1.06 \pm 0.04 \mathrm{MBq} /$ mouse. hrs: hours. Data was shown in Mean $\pm \mathrm{S} . \mathrm{E}$.

\begin{tabular}{c|c|c|c|c}
\hline \multirow{2}{*}{ Time } & \multicolumn{2}{|c|}{ Day 1 $(24 \mathrm{hrs})$} & \multicolumn{2}{c}{ Day 2 to 4 } \\
\hline Sex & Male & Female & Female \\
\hline Charcoal filter & $3.23 \pm 0.03$ & $2.63 \pm 0.062$ & $0.0019 \pm 0.00010$ & $0.0016 \pm 0.00013$ \\
\hline Feces & $6.04 \pm 0.35$ & $5.03 \pm 0.26$ & $2.59 \pm 0.034$ & $2.58 \pm 0.07$ \\
\hline Bedding & $86.03 \pm 10.38$ & $67.62 \pm 12.02$ & $0.013 \pm 0.00087$ & $0.0064 \pm 0.00022$ \\
\hline
\end{tabular}


Table 5 Evaluated \% ID (percentage of observed radioactivity) of excreted ${ }^{225} \mathrm{Ac}$ from normal mice after the administration. Day 1 (24 hrs), 2 to 5 days, and 6 to 12 days (Mean \pm S.E). ICR mice was used for this experiment. Each group was consisted with three mice $(\mathrm{N}=3)$. Injection dose was $9.87 \pm 0.04 \mathrm{kBq} / \mathrm{mouse}$. hrs: hours

\begin{tabular}{c|c|c|c|c}
\hline \multirow{2}{*}{ Time } & \multicolumn{2}{|c|}{ Day 1 $(24 \mathrm{hrs})$} & \multicolumn{2}{c}{ Day 2 to 5 } \\
\hline Sex & Male & Female & $0.21 \pm 0.0078$ & $0.013 \pm 0.0027$ \\
\hline Charcoal filter & $0.0063 \pm 0.0011$ & $0.27 \pm 0.044$ & $0.57 \pm 0.039$ & $0.16 \pm 0.022$ \\
\hline Feces & $1.12 \pm 0.029$ & $3.56 \pm 0.14$ & $0.99 \pm 0.083$ & $2.51 \pm 0.2$ \\
\hline Bedding & $5.98 \pm 1.40$ & $12.95 \pm 4.18$ & & Female \\
\hline
\end{tabular}

\begin{tabular}{c|c|c}
\hline \multirow{2}{*}{ Time } & \multicolumn{2}{|c}{ Day 6 to 12} \\
\hline Sex & Male & Female \\
\hline Charcoal filter & $0.043 \pm 0.0017$ & $0.13 \pm 0.01$ \\
\hline Feces & $0.21 \pm 0.0041$ & $0.20 \pm 0.0089$ \\
\hline Bedding & $0.26 \pm 0.040$ & $2.51 \pm 0.16$ \\
\hline
\end{tabular}

Table 6 Evaluated \%ID (percentage of observed radioactivity) of ${ }^{223} \mathrm{Ra}$ in wash water at 24 and $48 \mathrm{hrs}$ after the administration. ddY mice was used for normal $(\mathrm{N}=5)$, and Balb/c-nu/nu with PC-3 cells was used for tumor bearing $(\mathrm{N}=5)$. Data was shown in Mean \pm S.E. hrs: hours

\begin{tabular}{|c|c|c|c|c|c|c|c|}
\hline & & \multirow{2}{*}{ Paper towel } & \multicolumn{5}{|c|}{ Wash times } \\
\hline & & & 1 & 2 & 3 & 4 & 5 \\
\hline \multirow{2}{*}{ Normal } & $24 \mathrm{hrs}$ & $0.033 \pm 0.023$ & $0.00054 \pm 0.00035$ & N.D. & N.D. & N.D. & N.D. \\
\hline & $48 \mathrm{hrs}$ & $0.30 \pm 0.22$ & $0.0049 \pm 0.0022$ & N.D. & N.D. & N.D. & N.D. \\
\hline \multirow{2}{*}{ Prostate cancer } & $24 \mathrm{hrs}$ & $0.65 \pm 0.54$ & $0.0078 \pm 0.00043$ & N.D. & N.D. & N.D. & N.D. \\
\hline & $48 \mathrm{hrs}$ & $0.15 \pm 0.083$ & N.D. & N.D. & N.D. & N.D. & N.D. \\
\hline
\end{tabular}

N.D.: not detected

Table 7 Evaluated \%ID (percentage of observed radioactivity) of ${ }^{211} \mathrm{At}$ in wash water at 24 hrs after the administration. ddY mice was used for normal $(\mathrm{N}=5)$, and Balb/c-nu/nu with K1-NIS cells was used for tumor bearing $(\mathrm{N}=5)$. Data was shown in Mean \pm S.E. hrs: hours

\begin{tabular}{c|c|c|c|c|c|c}
\hline \multirow{2}{*}{} & \multirow{2}{*}{ Paper towel } & \multicolumn{5}{|c}{ Wash times } \\
\cline { 3 - 6 } & & 1 & 2 & 3 & 4 & 5 \\
\hline Normal & $0.41 \pm 0.14$ & $0.027 \pm 0.0039$ & N.D. & N.D. & N.D. & N.D. \\
\hline Tumor bearing & $0.014 \pm 0.0011$ & N.D. & N.D. & N.D. & N.D. & N.D. \\
\hline
\end{tabular}

N.D.: not detected

this study. The nuclide might be used for the label or it might be used as it is. Safety measures should be based not only on the nuclide but also on the nature of the compound.

\section{Conclusion}

For all the studied radionuclides, the dispersions evaluated from the charcoal-impregnated filters were negligibly low. 
Table 8 Evaluated \% ID (percentage of observed radioactivity) of $225 \mathrm{Ac}$ in wash water at 24 and $48 \mathrm{hrs}$ after the administration. ddY mice was used for normal $(\mathrm{N}=5)$. Data was shown in Mean \pm S.E. hrs: hours

\begin{tabular}{c|c|c|c|c|c|c|c}
\hline \multicolumn{2}{c|}{} & \multirow{2}{*}{ Paper towel } & \multicolumn{5}{c}{ Wash times } \\
\cline { 3 - 8 } \multicolumn{2}{c|}{} & & 1 & 2 & 3 & 4 & 5 \\
\hline \multirow{3}{*}{ Normal } & $24 \mathrm{hrs}$ & $0.033 \pm 0.024$ & N.D. & N.D. & N.D. & N.D. & N.D. \\
\cline { 2 - 8 } & $48 \mathrm{hrs}$ & $0.30 \pm 0.22$ & N.D. & N.D. & N.D. & N.D. & N.D. \\
\hline
\end{tabular}

Almost all the radionuclides were easily stripped with paper. These results confirm that ${ }^{223} \mathrm{Ra},{ }^{211} \mathrm{At}$ and ${ }^{225} \mathrm{Ac}$ are hardly dispersed around by appropriate safety measures.

The results of this study might also help to estimate the kinetics of radionuclides released by labeled compounds. In this study, the dispersion of ${ }^{211} \mathrm{At},{ }^{223} \mathrm{Ra}$ and ${ }^{225} \mathrm{Ac}$ was investigated in the animal experiments. Almost of all these three kinds of $\alpha$-emitting nuclides, we could collect with adsorbent, such as charcoal-impregnated filter and bedding. It was not found that remarkable difference of the diffusion in animal experiments between conventional beta-emitting nuclides and alpha-emitting nuclides ${ }^{19)}$. There was no unexpected dispersion and it was confirmed that conventional equipment was enough for protecting ourselves. In other words, the safety of animal experiments using $\alpha$-emitting radioisotopes was thought to be guaranteed by taking appropriate antiscattering measures as in chemical experiments.

\section{Acknowledgements}

The authors would like to thank Bayer Health Care Pharmaceuticals Inc. to kindly provide ${ }^{223} \mathrm{Ra}$ dichloride solutions. We also express their gratitude to the crew of the K140 AVF cyclotron of Research Center for Nuclear Physics, Osaka University for their excellent beam operation during the course of the ${ }^{211}$ At experiments. The ${ }^{211}$ At was partly supplied through Supply Platform of Short-lived Radioisotopes, supported by JSPS Grant-in-Aid for Scientific Research on Innovative Areas, Grant Number $16 \mathrm{H} 06278 .{ }^{225} \mathrm{Ac}$ was provided by a U-233 collaboration between JAEA and the Inter-University Cooperative Research Program of the Institute for Materials Research, Tohoku University (proposal no. 17K0204). We would like to thank Yoshihide Nakamura, Japan Radioisotope Association for his excellent technical supervision. This study was funded by a radiation safety regulation research strategic promotion project from the Nuclear Regulation Authority, Japan.

\section{References}

1) Ministry of Health, Labor and Welfare "Nationwide cancer incidence number 2016 preliminary report", https://www.mhlw. go.jp/content/10900000/000468976.pdf

2) Xofigo, for intravenous injection (radiopharmaceutical standard radium chloride $\left({ }^{223} \mathrm{Ra}\right)$ injection solution) package insert, https:// pharma-navi.bayer.jp/omr/online/product_material/XOF_ MPI_201810050_1538444913.pdf

3) Henriksen G, Breistøl K, Bruland $\varnothing \mathrm{S}$, Fodstad $\varnothing$, Larsen RH: Significant antitumor effect from bone-seeking, alpha-particleemitting (223)Ra demonstrated in an experimental skeletal metastases model, Cancer Res., 62, 3120-5 (2002).

4) Bruland $\varnothing \mathrm{S}$, Nilsson S, Fisher DR, Larsen RH: High-linear energy transfer irradiation targeted to skeletal metastases by the alpha-emitter ${ }^{223} \mathrm{Ra}$ : adjuvant or alternative to conventional modalities?, Clin Cancer Res., 12, 6250s-6257s (2006).

5) Kratochwil C, Bruchertseifer F, Giesel FL, Weis M, Verburg FA, Mottaghy F, Kopka K, Apostolidis C, Haberkorn U, Morgenstern A: ${ }^{225}$ Ac-PSMA-617 for PSMA-Targeted $\alpha$-Radiation Therapy of Metastatic Castration-Resistant Prostate Cancer., J Nucl Med., 57, 1941-1944 (2016).

6) Kratochwil C, Bruchertseifer F, Rathke H, Bronzel M, Apostolidis C, Weichert W, Haberkorn U, Giesel FL, Morgenstern A: Targeted $\alpha$-Therapy of Metastatic Castration-Resistant Prostate Cancer with (225)Ac-PSMA-617: Dosimetry Estimate and Empiric Dose Finding, J Nucl Med., 58, 1624-1631 (2017).

7) Kratochwil C, Bruchertseifer F, Rathke H, Hohenfellner M, Giesel FL, Haberkorn U, Morgenstern A: Targeted $\alpha$-Therapy of Metastatic Castration-Resistant Prostate Cancer with (225)AcPSMA-617: Swimmer-Plot Analysis Suggests Efficacy Regarding Duration of Tumor Control, J Nucl Med., 59, 795-802 (2018).

8) Nagata K, Shirasaki K, Toyoshima A, Ooe K, Yamamura T, Shinohara A, Yoshimura T: Dispersal rate of radon-219 from aqueous radium-223 solution containing sodium chloride/citrate, Radiation Safety Management, 19, 1-9 (2020).

9) Ooe K, Watabe T, Kamiya T, Yoshimura T, Hosono M, Shinohara A, Hatazawa J: Quantitative measurement of ${ }^{219} \mathrm{Rn}$ radioactivity in exhaled breath from patients with bone metastasis of castration-resistant prostate cancer treated with ${ }^{223} \mathrm{RaCl}_{2}$, EJNMMI Phys., 6, 13 (2019).

10) Yamamura T, Shirasaki K, Kikunaga $H$, Nagata K, Zhang Z, 
Washiyama K, Toyoshima A, Yoshimura T, Shinohara A: Transfer rates of ${ }^{225} \mathrm{Ac}$ to exhaust air, surface, and waste water under chemical operations, Radiation Safety Management, 19, 35-48 (2020).

11) Toyoshima A, Shinohara A: Nuclear chemistry of astatine (At), Radioisotopes, 67, 461-469 (2018).

12) Toyoshima A, Nagata $K$, Ooe $K$, Zhang $Z$, Ikeda $T$, Ichimura $S$, Obata H, Yoshimura T, Shinohara A: Dispersal rates of astatine-211 from aqueous solutions and chloroform, Radiation Safety Management, 18, 16-22 (2019).

13) Apostolidis C, Molinet R, Rasmussen G, Morgenstern A: Production of Ac-225 from Th-229 for targeted alpha therapy, Anal Chem., 77, 6288-6291 (2005).

14) Zielinska B, Apostolidis C, Bruchertseifer F, Morgenstern A: An improved method for the production of Ac-225/Bi-213 from Th-229 for targeted alpha therapy, Solvent Extr Ion Exc., 25, 339-349 (2007).

15) Watabe T, Kaneda K, Liu Y, Shirakami Y, Ooe K, Toyoshima A, Shimosegawa E, Fukuda M, Shinohara A, Hatazawa J: Enhancement of astatine-211 uptake via the sodium iodide symporter by the addition of ascorbic acid in targeted alpha therapy of thyroid cancer, J Nucl Med., 60, 1301-1307 (2019).
16) Lindholm PF, Hwang YS: LPA Increases Tumor Growth and Bone Destruction Through Enhancement of Osteoclastogenic Cytokines, Anticancer Res., 36, 61-70 (2016).

17) Watabe T, Liu Y, Kaneda-Nakashima K, Shirakami Y, Lindner T, Ooe K, Toyoshima A, Nagata K, Shimosegawa E, Haberkorn U, Kratochwil C, Shinohara A, Giesel F, Hatazawa J: Theranostics targeting fibroblast activation protein in the tumor stroma: $(64) \mathrm{Cu}$ and (225)Ac labelled FAPI-04 in pancreatic cancer xenograft mouse models, J Nucl Med., 61, 563-569 (2020).

18) Kaneda-Nakashima K, Zhang Z, Manabe Y, Shimoyama A, Kabayama K, Watabe T, Kanai Y, Ooe K, Toyoshima A, Shirakami Y, Yoshimura T, Fukuda M, Hatazawa J, Nakano T, Fukase K, Shinohara A: $\alpha$-Emitting cancer therapy using ${ }^{211}$ At-AAMT targeting LAT1, Cancer Sci., 112, 1132-1140 (2021).

19) Totsuka Z, Doi M, Miyazawa E, Kawakami T: Survey of literature on dispersion ratio and collection ratio of radioisotopes in animal study using radioisotopes, Radioisotopes, 47, 855-863 (1998).

20) The Japan Radioisotope Association: Radioisotope pocket data book 11th Edition (2011). 